\title{
Investigation of properties of contact connector of bimetallic hollow cylinder under the influence of electromagnetic pulse
}

\author{
Musii R. ${ }^{1}$, Melnyk N. ${ }^{1}$, Dmytruk V. ${ }^{1,2}$ \\ ${ }^{1}$ Lviv Polytechnic National University, \\ 12 S. Bandera Str., Lviv, 79013, Ukraine \\ ${ }^{2}$ Centre of Mathematical Modeling of Pidstryhach IAPMM, NAS of Ukraine \\ 15 Dudayev Str., Lviv, 79005, Ukraine
}

(Received 21 November 2018)

\begin{abstract}
A plane axisymmetric dynamic problem of thermomechanics for a hollow bimetallic cylinder under a uniform non-stationary electromagnetic action is formulated. The numerical analysis of the solution of this problem for a hollow bimetallic cylinder exposed to the influence of electromagnetic pulse is carried out The graphs of changes in the time of ponderomotive force, temperature, components of the tensor of dynamic stresses and intensity of stresses in the compound layers of a cylinder made of stainless steel and copper are presented. The dependences of the maximal values of the intensities of stresses in the layers of the cylinder on the magnitudes of the intensity of the magnetic field for different pulse durations are established, which allowed stating the permissible loads for the conductive bimetallic hollow cylinder as a contact connector.
\end{abstract}

Keywords: the problem of thermomechanics, bimetallic cylinder, bearing capacity, connector, electromagnetic pulse.

2000 MSC: $74 \mathrm{H} 10$

UDC: 539.3

DOI: $10.23939 / \mathrm{mmc} 2018.02 .193$

\section{Introduction}

In modern machines, mechanisms and structures, composites and piecewise-homogeneous conductive structural elements, in particular bimetallic solids of various geometric configurations, are widely used [1]. Such elements of constructions are in conditions of multifactor loads, including those of electromagnetic pulse character. Under the action of pulsed electromagnetic fields (PEMF), in these solids the non-stationary temperature fields and stresses emerge which for the certain parameters of EMF can reach critical values. In such conditions, the solid, as an element of the structure, loses its operability and properties of the contact connector.

In $[1,2]$, the technical means for creating strong and superstrong pulsed magnetic fields are considered. The physical processes that occur under the influence of such fields on the conducting materials are described. The paper [4] deals with the issues related to the electromagnetic treatment of materials. In $[5,6]$, the thermo-stressed state of homogeneous conductive bodies of canonical form under the action of electromagnetic pulses (EMP) is investigated. However, the literature does not sufficiently cover the issue of behavior of bimetallic bodies under such actions.

This work reports the results of a study of thermomechanical behavior, operability and properties of the contact connector of a bimetallic hollow cylinder under the effects of EMP. In the paper, a planar axisymmetric dynamic problem of thermomechanics for the cylinder under consideration is formulated for a homogeneous non-stationary electromagnetic action. On the basis of the general solution of this problem, the thermomechanical behavior of the considered cylinder under the influence of EMP is numerically analyzed. 


\section{Statement of the problem}

Consider a long elastic hollow bimetallic cylinder with the inner $r=r_{0}$ and outer $r=r_{2}$ surfaces, which is referenced to a cylindrical system of coordinates $(r, \varphi, z)$ whose axis $O z$ coincides with the axis of the cylinder. The materials of composite layers of a cylinder are homogeneous isotropic nonferromagnetic, and their physical and mechanical characteristics are constant. The non-stationary EMF acting on the cylinder is given by the values of the axial component $H_{z}^{(n)}(r, t)$ of the magnetic field strength vector $\boldsymbol{H}^{(n)}$ on the inner $r=r_{0}$ and outer $r=r_{2}$ surfaces of the cylinder.

The outer surfaces of the cylinder are insulated from the environment and free of the loading. The conditions of ideal electromagnetic, thermal and mechanical contacts are fulfilled on the surface $r=r_{1}$ of the compound layers. The cylinder is under the condition of a flat deformation. Accordingly, all the defining functions of the problem, which are the axial component $H_{z}^{(n)}(r, t)$ of the magnetic field strength vector, the temperature $T^{(n)}(r, t)$, and the nonzero radial component $u_{r}^{(n)}(r, t)$ of the displacement vector $\boldsymbol{u}^{(n)}(r, t)$ are functions of the radial coordinate $r$ and time $t$.

To study the thermomechanical behavior of the considered cylinder and its bearing capacity under the pulsed electromagnetic actions by means of the determined component $u_{r}^{(n)}(r, t)=u_{r}^{(n) Q}(r, t)+$ $u_{r}^{(n) F}(r, t)$ of the total displacements caused by the Joule heat $Q^{(n)}(r, t)$ and ponderomotive force $F_{r}^{(n)}(r, t)$, we determine the components $\sigma_{j j}^{(n)}(r, t),(j=r, \varphi, z)$ of the tensor $\hat{\sigma}^{(n)}=\hat{\sigma}^{(n) Q}+\hat{\sigma}^{(n) F}$ of the total dynamic stresses in the $n$-compound layer of the cylinder. On the basis of the obtained $\sigma_{j j}^{(n)}(r, t)$, we calculate the intensity $\sigma_{i}^{(n)}(r, t)$ of the tensor of the total stresses according to the formula [7]

$$
\sigma_{i}^{(n)}=\sqrt{\left(3 I_{2}\left(\hat{\sigma}^{(n)}\right)-I_{1}^{2}\left(\hat{\sigma}^{(n)}\right)\right) / 2}
$$

where $I_{j}\left(\hat{\sigma}^{(n)}\right),(j=1,2)$ is the $\mathrm{j}$-th invariant of the stress tensor $\hat{\sigma}^{(n)}$. In order to evaluate the bearing capacity of a bimetallic cylinder in accordance with the well-known Guber-Mises criterion for homogeneous bodies, we verify the fulfillment of the condition [8]

$$
\max \sigma_{i}^{(n)}<\sigma_{d}^{(n)}
$$

The bimetallic cylinder loses its bearing capacity as a whole if at least one of the compound layers loses it, i.e. the condition (2) is violated. Here $\sigma_{d}^{(n)}$ is the limit of the elastic deformation of the material of the $n$-th layer of the cylinder. The properties of a contact connector of the cylinder are preserved if the values of the intensities of stresses $\sigma_{i}^{(n) *}$ in each layer on the interface do not exceed the strength $\sigma_{M}$ of the contact connector, i.e., the condition [8]

$$
\max \sigma_{i}^{(n) *}<\sigma_{M}
$$

According to the chosen solving model of the problem of thermomechanics under consideration, the EMF, temperature, thermo-stressed state, and bearing capacity of the cylinder are determined successively.

\subsection{The EMF determination}

The nonzero axial component $H_{z}^{(n)}(r, t)$ of the magnetic field strength vector in each of $n$-th compound layer of the cylinder is determined from the equation

$$
\frac{\partial^{2} H_{z}^{(n)}}{\partial r^{2}}+\frac{1}{r} \frac{\partial H_{z}^{(n)}}{\partial r}-\sigma_{n} \mu_{n} \frac{\partial H_{z}^{(n)}}{\partial t}=0
$$

Mathematical Modeling and Computing, Vol.5, No. 2, pp. 193-200 (2018) 
under the boundary conditions

$$
H_{z}^{(1)}\left(r_{0}, t\right)=H_{z}^{-}(t), \quad H_{z}^{(2)}\left(r_{2}, t\right)=H_{z}^{+}(t)
$$

on the inner $r=r_{0}$ and outer $r=r_{2}$ surfaces of the cylinder, the conditions of an ideal electromagnetic contact [9-11]

$$
H_{z}^{(1)}\left(r_{1}, t\right)=H_{z}^{(2)}\left(r_{1}, t\right), \quad \frac{\partial H_{z}^{(1)}\left(r_{1}, t\right)}{\partial r}=k_{\sigma} \frac{\partial H_{z}^{(2)}\left(r_{1}, t\right)}{\partial r}
$$

on the surface $r=r_{1}$ of the interface of compound layers, as well as under the initial conditions

$$
H_{z}^{(n)}(r, 0)=0
$$

Here, $\sigma_{n}, \mu_{n}$ are the coefficients of electrical conductivity and the magnetic permeability of the compounds of the cylinder $k_{\sigma}=\sigma_{1} / \sigma_{2}$. By means of the obtained function $H_{z}^{(n)}(r, t)$, the specific densities of the Joule heat $Q^{(n)}(r, t)$, and the ponderomotive strength $\boldsymbol{F}^{(n)}=\left\{F_{r}^{(n)}(r, t) ; 0 ; 0\right\}$ are determined according to the formulas

$$
Q^{(n)}=\frac{1}{\sigma_{n}}\left(\frac{\partial H_{z}^{(n)}}{\partial r}\right)^{2}, \quad F_{r}^{(n)}=-\mu_{n} H_{z}^{(n)} \frac{\partial H_{z}^{(n)}}{\partial r} .
$$

\subsection{The temperature field determination}

In the second stage, by means of the determined specific densities of the Joule heat $Q^{(n)}(r, t)$, the distribution of the temperature field $T^{(n)}(r, t)$ in each $n$-th compound layer of the cylinder is determined from the heat equation

$$
\frac{\partial^{2} T^{(n)}}{\partial r^{2}}+\frac{1}{r} \frac{\partial T^{(n)}}{\partial r}-\frac{1}{\kappa_{n}} \frac{\partial T^{(n)}}{\partial t}=-\frac{Q^{(n)}}{\lambda_{n}}
$$

Eq. (8) is solved taking into account the boundary conditions of thermal insulation

$$
\frac{\partial T^{(1)}\left(r_{0}, t\right)}{\partial r}=0, \quad \frac{\partial T^{(2)}\left(r_{2}, t\right)}{\partial r}=0
$$

on the inner $r=r_{0}$ and outer $r=r_{2}$ surfaces of the cylinder, the conditions of ideal thermal contact [10, $11]$

$$
T^{(1)}\left(r_{1}, t\right)=T^{(2)}\left(r_{1}, t\right), \quad \frac{\partial T^{(1)}\left(r_{1}, t\right)}{\partial r}=k_{\lambda} \frac{\partial T^{(2)}\left(r_{1}, t\right)}{\partial r}
$$

on the surface $r=r_{1}$ of the connection of the compound layers of the cylinder and the initial condition

$$
T^{(n)}(r, 0)=0 .
$$

Here, $\kappa_{n}, \lambda_{n}$ are the coefficients of temperature and heat conductivity of the material of the $n$-th layer of the cylinder, $k_{\lambda}=\lambda_{2} / \lambda_{1}$.

\subsection{The thermo-stressed state determination}

To determine the radial $\sigma_{r r}^{(n)}$, circular $\sigma_{\varphi \varphi}^{(n)}$ and axial $\sigma_{z z}^{(n)}$ components of the tensor of dynamic stresses $\hat{\sigma}^{(n)}(r, t)$ different from zero, in each $n$-th compounds of the cylinder we choose as a basic the system of equations of a planar axisymmetric dynamic problem of thermoelasticity for cylinders in displacements $[10,11]$. 
The nonzero radial component $u_{r}^{(n)}(r, t)$ of the displacement vector $\boldsymbol{u}^{(n)}(r, t)$, in each $n$-th compounds of the cylinder is determined from the equation $[10,11]$

$$
\frac{\partial^{2} u_{r}^{(n)}}{\partial r^{2}}+\frac{1}{r} \frac{\partial u_{r}^{(n)}}{\partial r}-\frac{u_{r}^{(n)}}{r^{2}}-\frac{1}{c_{n}^{2}} \frac{\partial^{2} u_{r}^{(n)}}{\partial t^{2}}=\alpha_{n} \frac{1+\nu_{n}}{1-\nu_{n}} \frac{\partial T^{(n)}}{\partial r}-\frac{\left(1+\nu_{n}\right)\left(1-2 \nu_{n}\right)}{E_{n}\left(1-\nu_{n}\right)} F_{r}^{(n)}
$$

under the boundary conditions

$$
\begin{aligned}
& \frac{\partial u_{r}^{(1)}\left(r_{0}, t\right)}{\partial r}+\frac{\nu_{1}}{1-\nu_{1}} \frac{u_{r}^{(1)}\left(r_{0}, t\right)}{r_{0}}=\alpha_{1} \frac{1+\nu_{1}}{1-\nu_{1}} T^{(1)}\left(r_{0}, t\right), \\
& \frac{\partial u_{r}^{(2)}\left(r_{2}, t\right)}{\partial r}+\frac{\nu_{2}}{1-\nu_{2}} \frac{u_{r}^{(2)}\left(r_{2}, t\right)}{r_{2}}=\alpha_{2} \frac{1+\nu_{2}}{1-\nu_{2}} T^{(2)}\left(r_{2}, t\right)
\end{aligned}
$$

on the inner $r=r_{0}$ and outer $r=r_{2}$ surfaces of the cylinder free of loading, under the conditions of an ideal mechanical contact $[9,10]$

$$
u_{r}^{(1)}\left(r_{1}, t\right)=u^{(2)}\left(r_{1}, t\right)
$$

$$
\begin{aligned}
&\left(1-\nu_{1}\right) \frac{\partial u_{r}^{(1)}\left(r_{1}, t\right)}{\partial r}+\nu_{1} \frac{u_{r}^{(1)}\left(r_{1}, t\right)}{r_{1}}-\alpha_{1}\left(1+\nu_{1}\right) T^{(1)}\left(r_{1}, t\right)= \\
&=k_{E}\left[\left(1-\nu_{2}\right) \frac{\partial u_{r}^{(2)}\left(r_{1}, t\right)}{\partial r}+\nu_{1} \frac{u_{r}^{(2)}\left(r_{1}, t\right)}{r_{1}}-\alpha_{2}\left(1+\nu_{2}\right) T^{(2)}\left(r_{1}, t\right)\right]
\end{aligned}
$$

on the surface $r=r_{1}$ of the connection of the compound layers of the cylinder and under the initial conditions

$$
u_{r}^{n)}(r, 0)=0, \quad \frac{\partial u_{r}^{(n)}(r, 0)}{\partial r}=0
$$

Here $c_{n}=\sqrt{E_{n}\left(1-\nu_{n}\right) /\left(\rho_{n}\left(1+\nu_{n}\right)\left(1-2 \nu_{n}\right)\right)}$ is the velocity of the elastic wave of expansion; $\nu_{n}$, $\alpha_{n}$ are the Poisson coefficients and linear thermal expansion, $E_{n}$ is the Young modulus, $\rho_{n}$ is the density of materials of the compound layers of the cylinder, $k_{E}=E_{1} /\left(1+\nu_{1}\right) /\left(E_{2} /\left(1+\nu_{2}\right)\right)$.

By the radial component $u_{r}^{(n)}(r, t)$ of the vector of total displacements, the nonzero components $\sigma_{j j}^{(n)}(j=r, \varphi, z)$ of the tensor of dynamic stresses in the $n$-layer are determined by the formulas

$$
\begin{gathered}
\sigma_{r r}^{(n)}=\frac{\mathrm{E}_{n}}{\left(1+\nu_{n}\right)\left(1-2 \nu_{n}\right)}\left[\left(1-\nu_{n}\right) \frac{\partial u_{r}^{(n)}}{\partial r}+\nu_{n} \frac{u_{r}^{(n)}}{r}-\alpha_{n}\left(1+\nu_{n}\right) T^{(n)}\right], \\
\sigma_{\varphi \varphi}^{(n)}=\frac{E_{n}}{\left(1+\nu_{n}\right)\left(1-2 \nu_{n}\right)}\left[\left(1-\nu_{n}\right) \frac{u_{r}^{(n)}}{r}+\nu_{n} \frac{\partial u_{r}^{(n)}}{\partial r}-\alpha_{n}\left(1+\nu_{n}\right) T^{(n)}\right], \\
\sigma_{z z}^{(n)}=\nu_{n}\left(\sigma_{r r}^{(n)}+\sigma_{\varphi \varphi}^{(n)}\right)-\alpha_{n} E_{n} T^{(n)} .
\end{gathered}
$$

The components $u_{r}^{(n) Q}, \sigma_{j j}^{(n) Q}$ are determined from the relations (12)-(18), taking $F_{r}^{(n)}=0$; and the components $u_{r}^{(n) F}, \sigma_{j j}^{(n) F}$, taking $T^{(n)}=0$. By means of the determined total stresses $\sigma_{j j}^{(n)}$, according to the formula (1) we determine the intensity of the stresses $\sigma_{i}^{(n)}$ in each of the cylinder compounds and their values are verified for the fulfillment of the conditions (2), (3). 


\section{Method of construction of solutions of the initial-boundary value problems}

For the construction of solutions of the initial-boundary value problems of electrodynamics (4)-(7), of thermal conductivity (8)-(11) and of thermoelasticity (12)-(15), the distribution of all defining functions $\Phi^{(n)}(r, t)=\left\{H_{z}^{(n)}(r, t), T^{(n)}(r, t), u_{r}^{(n)}(r, t)\right\}$ in the thickness of each compound layer of the cylinder is approximated by quadratic polynomials of the form

$$
\Phi^{(n)}(r, t)=\sum_{i=0}^{2} a_{i}^{\Phi(n)}(t) r^{i} .
$$

The coefficients $a_{i}^{\Phi(n)}(t)$ of the polynomials (19) are determined through the integral (total in a two-layer package) characteristics $\Phi_{s}(t)$ of the defining functions $\Phi^{(n)}(r, t)$

$$
\Phi_{s}(t)=\sum_{n=1}^{2} \int_{r_{n-1}}^{r_{n}} \Phi^{(n)}(r, t) r^{s} d r, \quad s=1,2
$$

and through the given boundary conditions on the outer surfaces and on the interfaces of the cylinder layers.

To find the integral characteristics $\Phi_{s}(t)$ of the desired functions $\Phi^{(n)}(r, t)$, the initial equations (4), (8) and (12) are integrated according to Eq. (20) taking into account the expressions (19). As a result, the initial-boundary value problems for the defining functions $\Phi^{(n)}(r, t)$ are reduced to the corresponding Cauchy problems for the integral characteristics $\Phi_{s}(t)$ of these functions. The solutions of the Cauchy problem for a homogeneous electromagnetic action are found using Laplace transform with respect to the time. Correspondingly, the expressions of the defining functions are obtained in the form:

$$
\begin{gathered}
H_{z}^{(n)}(r, t)=\sum_{i=0}^{2}\left[\sum_{s=1}^{2} a_{i s}^{(n)} \sum_{k=1}^{2} \int_{0}^{t}\left(A_{s 1}(k) H_{j}^{-}(\tau)+A_{s 2}(k) H_{j}^{+}(\tau)\right) e^{p_{k}(t-\tau)} d \tau+a_{i 3}^{(n)} H_{j}^{-}(t)+a_{i 4}^{(n)} H_{j}^{+}(t)\right] r^{i}, \\
T^{(n)}(r, t)=\sum_{k=0}^{2} \sum_{s=1}^{2}\left[b_{k s}^{(n)} \sum_{m=1}^{2} \int_{0}^{t}\left(B_{s 1}(m) W_{1}^{Q}(\tau)+B_{s 2}(m) W_{2}^{Q}(\tau)\right) e^{p_{m}(t-\tau)} d \tau\right] r^{k}, \\
u_{r}^{(n)}(r, t)=\sum_{i=0}^{2}\left[\sum_{s=1}^{2} c_{i s}^{(n)} \sum_{\beta=1}^{4} \int_{0}^{t}\left(R_{s 1}^{*}(\beta) W_{1}^{*}(\tau)+R_{s 2}^{*}(\beta) W_{2}^{*}(\tau)\right) e^{p_{\beta}(t-\tau)} d \tau\right] r^{i} .
\end{gathered}
$$

Here, $W_{s}^{Q}(t), W_{s}^{*}(t)$ are the expressions of the integrated in accordance with the relation (2) right-hand sides of Eqs. (8) and (12); $A_{s j}(k), B_{s j}(m), R_{s j}^{*}(\beta)(s, j=1,2)$ are the expressions that depend on the roots $p_{k}, p_{m}, p_{\beta}$ of the corresponding characteristic equations of the problems for determining the integral characteristics of the functions $H_{z}^{(n)}, T^{(n)}$, and $u_{r}^{(n)} ; a_{i s}^{(n)}, b_{k s}^{(n)}, c_{i s}^{(n)}$ are numerical coefficients depending on the geometrical and physico-mechanical parameters of the cylinder layers.

\section{Numerical analysis of the problem for uniform EMP}

The action of EMP mathematically can be described by the function [6]:

$$
H_{z}\left(r_{0}, t\right)=H_{z}\left(r_{2}, t\right)=k H_{0}\left(e^{-\beta_{1} t}-e^{-\beta_{2} t}\right) .
$$

Here $H_{0}$ is the maximal value of the intensity of the magnetic field in the pulse, $k$ is the normalization factor, $\beta_{1}$ and $\beta_{2}$ are the parameters characterizing the times of the fronts of growth and decrease 
of the pulse. Substituting the expression (24) into relations (21)-(23), the solution of the problem of thermomechanics for the bimetallic cylinder under consideration is described. On the basis of
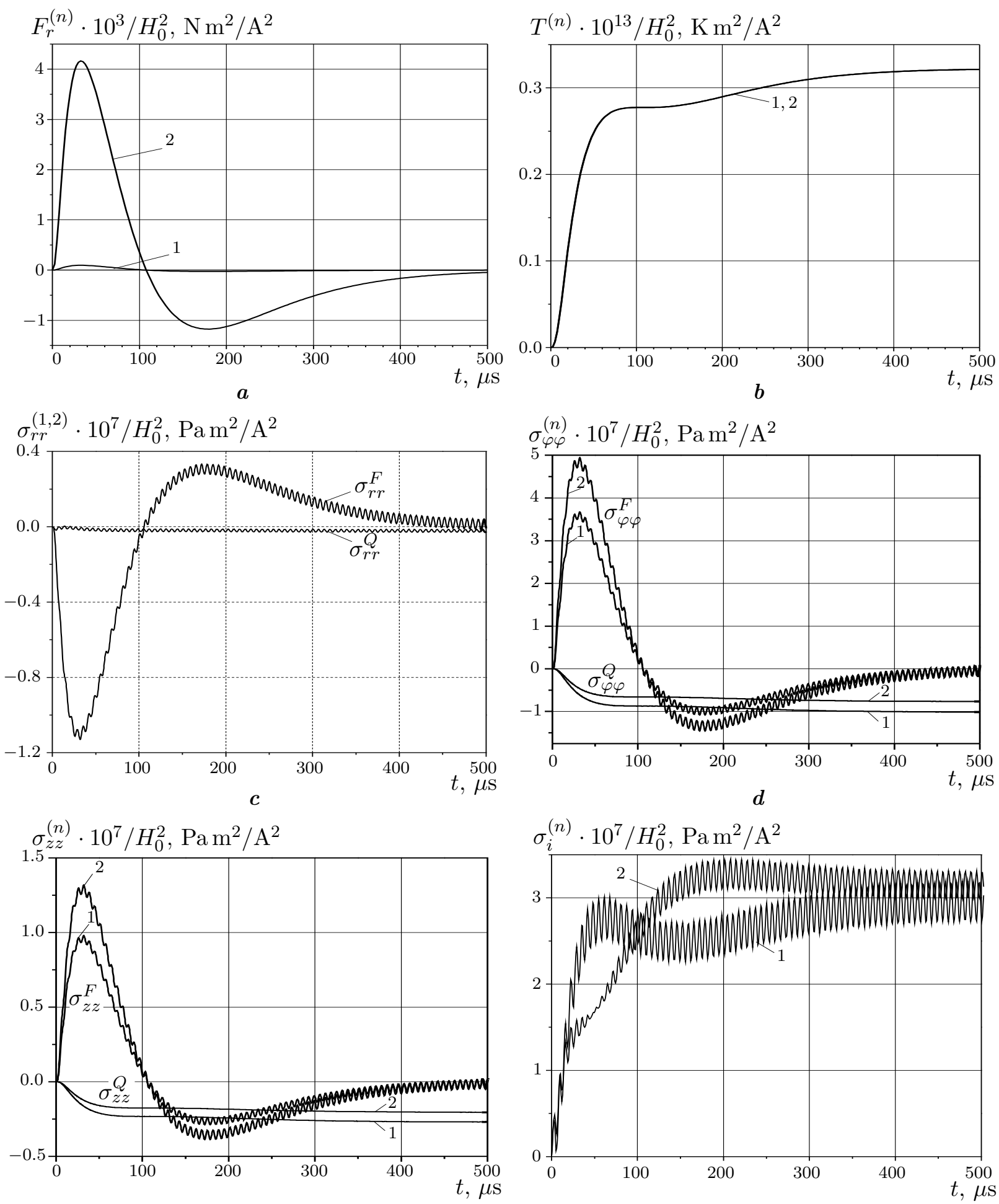

$e$

$f$

Fig. 1. Change in time $t$ of ponderomotive force $F_{r}^{(n)}(\boldsymbol{a})$, temperature $T^{(n)}(\boldsymbol{b})$, components $\sigma_{r r}^{(n) F}, \sigma_{r r}^{(n) Q}$ of radial stresses $\sigma_{r r}^{(n)}(\boldsymbol{c})$, components $\sigma_{\varphi \varphi}^{(n) F}, \sigma_{\varphi \varphi}^{(n) Q}$ of circular stresses $\sigma_{\varphi \varphi}^{(n)}(\boldsymbol{d})$, components $\sigma_{z z}^{(n) F}, \sigma_{z z}^{(n) Q}$ of axial stresses $\sigma_{z z}^{(n)}(\boldsymbol{e})$, and intensity $\sigma_{i}^{(n)}$ of total stresses $\sigma_{i}^{(n)}(\boldsymbol{f})$ on the interface of compound layers. Curves 1, 2 $(\boldsymbol{a}, \boldsymbol{b}, \boldsymbol{d}, \boldsymbol{e}, \boldsymbol{f})$ correspond to the values of variables under consideration in the first and second layers of the cylinder. 
the obtained solution, a numerical analysis of the thermo-stressed state and bearing capacity of a bimetallic cylinder made of stainless steel and copper with radii of surfaces $r_{0}=8 \mathrm{~mm}, r_{1}=9 \mathrm{~mm}$ and $r_{2}=10 \mathrm{~mm}$. There were chosen equal parameters of EMP, the durations $t_{i}=100 \mu \mathrm{s}, 1000 \mu \mathrm{s}, k=2.5$, $\beta_{1}=-\ln \varepsilon / t_{i}, \beta_{2}=2 \beta_{1}, \varepsilon=0.001$. The results of numerical studies of the thermo-stressed state and the bearing capacity of the cylinder for the specified time parameters of the EMP and the geometric parameters of the cylinder and the chosen materials of the compound layers are presented in Figs. 1,2.

Fig. 1 illustrates the change in the time $t$ of the ponderomotive force $F_{r}^{(n)}(\boldsymbol{a})$, the temperature $T^{(n)}(\boldsymbol{b})$, the components $\sigma_{r r}^{(n) F}, \sigma_{r r}^{(n) Q}$ of the radial stresses $\sigma_{r r}^{(n)}(\boldsymbol{c})$, the components $\sigma_{\varphi \varphi}^{(n) F}, \sigma_{\varphi \varphi}^{(n) Q}$ of the circular stresses $\sigma_{\varphi \varphi}^{(n)}$ $(\boldsymbol{d})$, the components $\sigma_{z z}^{(n) F}, \sigma_{z z}^{(n) Q}$ of the axial stresses $\sigma_{z z}^{(n)}$ $(\boldsymbol{e})$, and the intensities of total stresses $\sigma_{i}^{(n)}(\boldsymbol{f})$ on the interfaces of the compound layers of the cylinder for the duration of EMP $t_{i}=1000 \mu \mathrm{s}$.

The curves 1, 2 in Fig. $1(\boldsymbol{a}, \boldsymbol{b}, \boldsymbol{d}, \boldsymbol{e}, \boldsymbol{f})$ correspond to the values of the considered quantities in the first and second layers of the cylinder. In Fig. 2, the dependences of the maximal stress intensity $\sigma_{i}^{(n)}$ values $\sigma_{i \max }^{(n)}$ on the magnitude of $H_{0}$ under the EMP actions $\left(H_{0 \max }=10^{7} \mathrm{~A} / \mathrm{m}\right)$ in the compound layers of the cylinder on their interfaces for the durations $t_{i}=100 \mu \mathrm{s}, 1000 \mu \mathrm{s}$ are given. The solid curves correspond to steel layer, and dashed curves - to copper layers. The point of crossing the horizontal lines corresponding to the values $\sigma_{d}^{(2)}$ and $\sigma_{M}$ with constructed curves of dependencies, allows us to determine the critical parameters of the EMP action, for which the considered

$\sigma_{i \max }^{(n)}, \mathrm{MPa}$

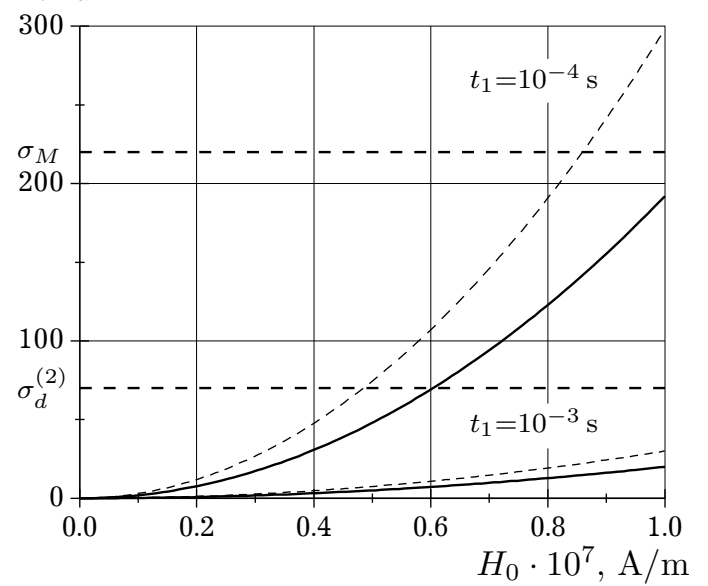

Fig. 2. Dependence of maximal values $\sigma_{i \max }^{(n)}$ of stress intensity $\sigma_{i}^{(n)}$ on the $H_{0}$ values in steel (solid curves) and copper (dashed curves) layers of the cylinder on their interfaces for the actions of EMP of durations $t_{i}=100 \mu \mathrm{s}, 1000 \mu \mathrm{s}$. cylinder loses its bearing capacity and the properties of the contact connector.

\section{Conclusions}

The values of the components $\sigma_{j j}^{(n) Q}$ and $\sigma_{j j}^{(n) F}$ and stresses $\sigma_{j j}^{(n)}$ are the magnitudes of the same order, and the effect of stresses $\sigma_{i j}^{(n) F}$ on the dynamic nature of the change in the time of total stresses is significant during the time of growth $t_{i n e r}$ of the pulse. With decreasing the EMP duration $t_{i}$, the maximal values of $F_{r}^{(n)}, T^{(n)}$, stresses $\sigma_{j j}^{(n) F}$ and $\sigma_{j j}^{(n) Q}$, and their intensities $\sigma_{i}^{(n)}$ increase. It is established that the bearing capacity and properties of the contact connector of the cylinder for the duration of the EMP actions $t_{i}=1000 \mu \mathrm{s}$ are preserved, but for $t_{i}=100 \mu \mathrm{s}$ are lost.

[1] Matthews F., Rawlings R. Composite materials: engineering and science. London, Chapman\&Hall (1994).

[2] Herlach F. Pulsed Magnets. Rep. Prog. Phys. 62 (6), 859-920 (1999).

[3] Shneerson G. A., Dolotenko M. I., Krivosheev S. I. Strong and Superstrong Pulsed Magnetic Fields Generation. De Gruyter (2010).

[4] Asai S. Electromagnetic Processing of Materials. Springer, Netherlands (2012).

[5] Hachkevych O. R., Musii R. S., Melnyk N. B. Thermomechanical behavior of a hollow conductive cylinder under pulsed electromagnetic action. Mat. Metody Fiz.-Mekh. Polya. 44 (1), 146-154 (2001), (in Ukrainian).

[6] Musiy R. S. Dynamic problems of thermomechanics of conducting bodies of canonical form. Lviv, Rastr-7 (2010), (in Ukrainian). 
[7] Ionov V. N., Ogibalov P. M. Stresses in bodies under impulsive loading. Moscow, Vyshayia Shkola (1975), (in Russian).

[8] Musii R., Melnyk N., Dmytruk V. Thermoelastic processes analyzer for piecewise homogeneous conductive structures subjected to pulsed electromagnetic action. Journal of Thermal Stresses. 41 (9), 1125-1135 (2018).

[9] Podstrigach Ya. S., Kolyano Yu. M. Generalized thermomechanics. Kiev, Naukova Dumka (1976), (in Russian).

[10] Podstrigach Ya. S., Burak Ya. I., Gachkevich A. R., Chernyavskaya L. V. Thermoelasticity of electrically conductive bodies. Kiev, Naukova Dumka (1977), (in Russian).

[11] Gribanov V.F., Panichkin N. G. Coupled and dynamic problems of thermoelasticity. Moscow, Mashinostroenie (1984).

\title{
Дослідження властивостей контактного з'єднання біметалевого порожнистого циліндра за дії електромагнітного імпульсу
}

\author{
Мусій P. ${ }^{1}$, Мельник H. ${ }^{1}$, Дмитрук B. ${ }^{1,2}$ \\ ${ }^{1}$ Національний університет "Львівсъка політехніка", \\ вул. Степана Бандери, 12, Львів, 79013, Украӥна \\ ${ }^{2}$ Центр математичного модулювання ІППММ НАН України, \\ вул. Дудаєва, 15, Лъвів, 79005, Україна
}

\begin{abstract}
Сформульовано плоску осесиметричну динамічну задачу термомеханіки для порожнистого біметалевого циліндра за однорідної нестаціонарної електромагнітної дії. Чисельно проаналізовано розв'язок задачі для порожнистого біметалевого циліндра за дії на нього електромагнітного імпульсу. Наведено графіки зміни в часі пондеромоторної сили, температури, компонент тензора динамічних напружень та інтенсивності напружень у складових шарах циліндра, виготовлених з нержавної сталі та міді. Встановлено залежності максимальних значень інтенсивностей напружень у шарах циліндра від величини напруженості магнітного поля за різних тривалостей імпульсу, що дало змогу встановити допустимі навантаження на електропровідний біметалевий порожнистий циліндр як контактне з'єднання.
\end{abstract}

Ключові слова: задача термомеханіки, біметалевий ииліндр, несуча здатність, контактне з'єднання, електромагнітний імпульс.

2000 MSC: $74 \mathrm{H} 10$

УдК: 539.3 